Hans van Ditmarsch, Wiebe van der Hoek, and Barteld Kooi

\title{
Dynamic Epistemic Logic
}

October 12, 2006

\section{Springer}

Berlin Heidelberg New York

Hong Kong London

Milan Paris Tokyo 



\section{Contents}

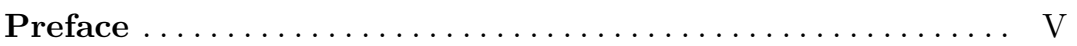

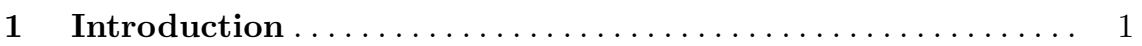

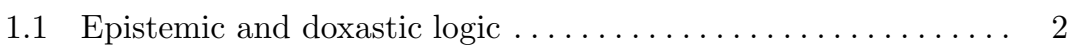

1.2 Dynamic epistemic logic . . . . . . . . . . . . . . 3

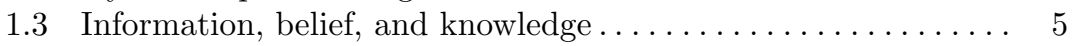

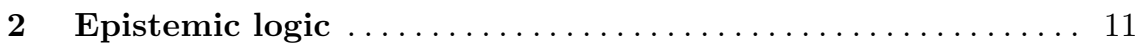

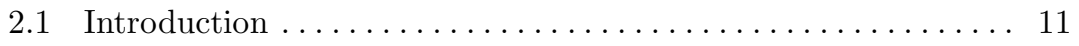

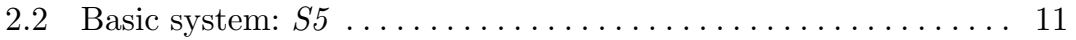

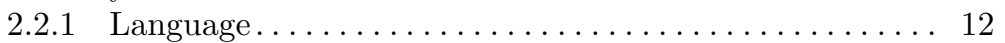

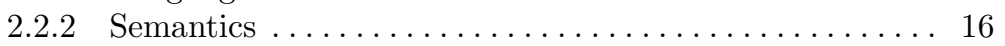

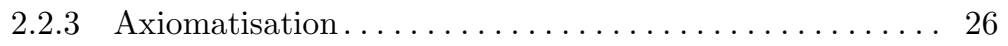

2.3 Group notions of knowledge $\ldots \ldots \ldots \ldots \ldots \ldots \ldots \ldots \ldots \ldots$

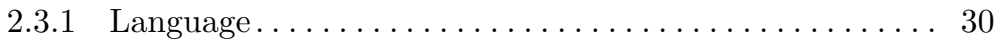

2.3 .2 Semantics ............................ 33

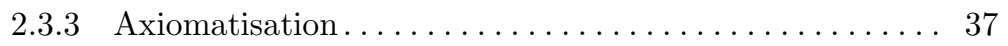

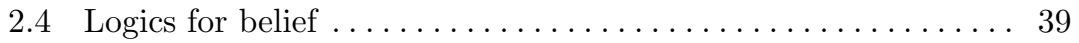

2.5 Notes . . . . . . . . . . . . . . . . . . . . . . . . . . . . . . . 40

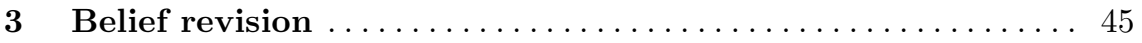

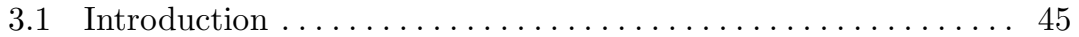

3.2 The AGM-approach $\ldots \ldots \ldots \ldots \ldots \ldots \ldots \ldots \ldots \ldots \ldots \ldots \ldots \ldots$

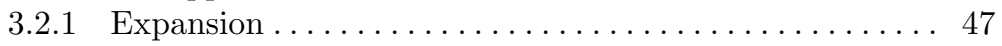

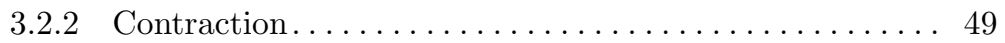

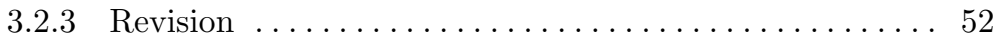

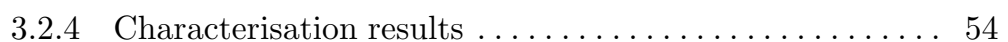

3.3 Possible worlds semantics for information change . . . . . . . 57

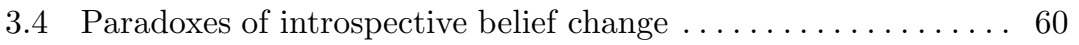

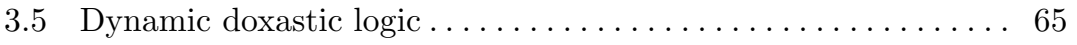

3.6 Notes . . . . . . . . . . . . . . . . . . . . . . . . . . 67 
4 Public announcements . . . . . . . . . . . . . . . . . . . . 69

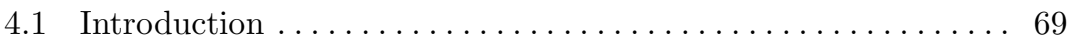

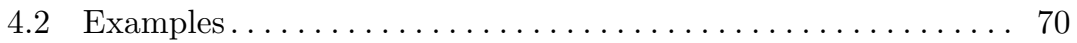

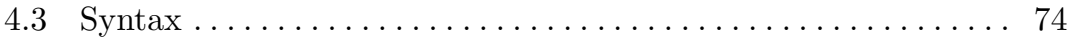

4.4 Semantics ........................... 76

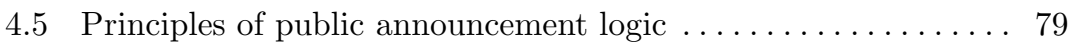

4.6 Announcement and common knowledge $\ldots \ldots \ldots \ldots \ldots \ldots . \ldots . \ldots$

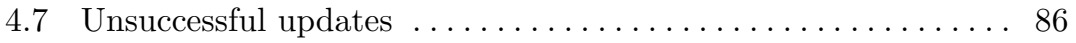

4.8 Axiomatisation ....................... 91 4.8.1 Public announcement logic without common knowledge 91

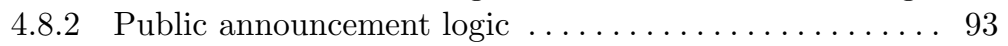

4.9 Knowledge and belief $\ldots \ldots \ldots \ldots \ldots \ldots \ldots \ldots \ldots \ldots \ldots$

4.10 Muddy Children........................... 95

4.11 Sum and Product $\ldots \ldots \ldots \ldots \ldots \ldots \ldots \ldots \ldots \ldots \ldots \ldots \ldots$

4.12 Russian Cards . . . . . . . . . . . . . . . . . . . . . . . . 100

4.13 Notes . . . . . . . . . . . . . . . . . . . . . . 107

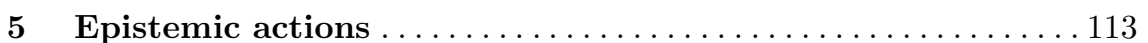

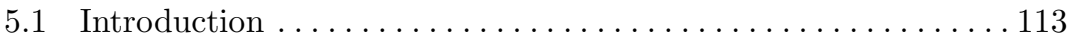

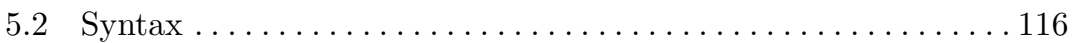

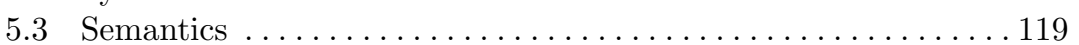

5.3 .1 Basic definitions . . . . . . . . . . . . . . . . . . . . 119

5.3 .2 Example of epistemic action semantics . . . . . . . . 122

5.3 .3 Semantic properties................... 124

5.3.4 Deterministic and nondeterministic actions ........ 126

5.3 .5 Valid properties of the logic . . . . . . . . . . . . 128

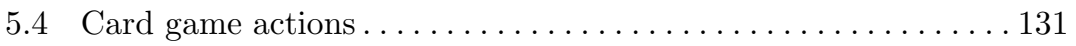

5.4 .1 Dealing and picking up cards . . . . . . . . . . . 131

5.4 .2 Game actions in Hexa. . . . . . . . . . . . . . . . . . . . . . . . 132

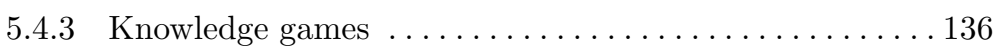

5.4 .4 Different cards . . . . . . . . . . . . . . . . . 137

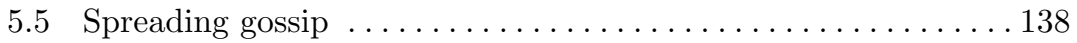

5.6 Notes . . . . . . . . . . . . . . . . . . . . . . . . . . . . . . 141

6 Action models . . . . . . . . . . . . . . . . . . . . . . . 145

6.1 Introduction . . . . . . . . . . . . . . . . . . . . . . 145

6.1 .1 Syntax or semantics? . . . . . . . . . . . . . . 150

6.1 .2 Action models as syntactic objects............. 150

6.1 .3 Action models as semantic objects . . . . . . . . . . 152

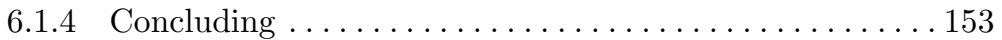

6.2 Action models . . . . . . . . . . . . . . . . . . . . . . 153

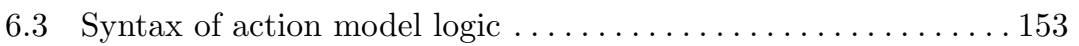

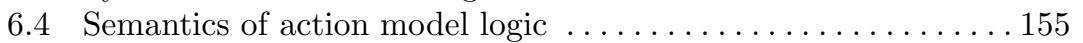

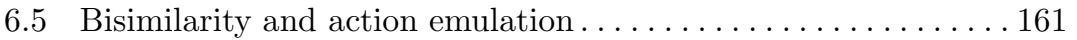

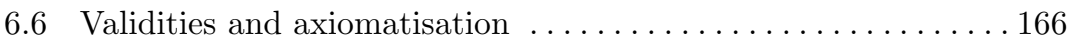


6.7 Epistemic model checking . . . . . . . . . . . . . . . . . . . . 170

6.8 Relational actions and action models . . . . . . . . . . . . . 174

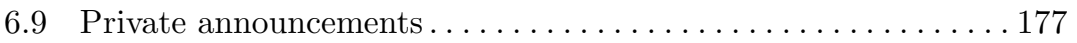

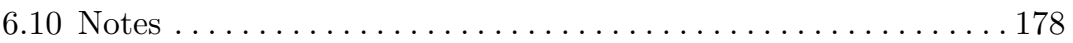

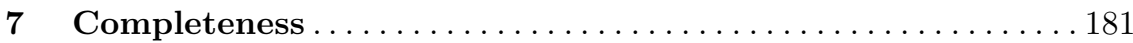

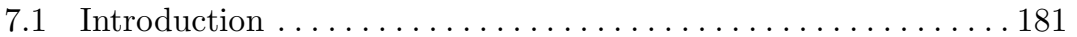

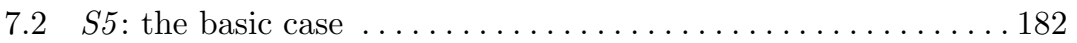

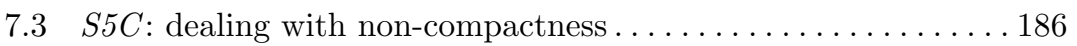

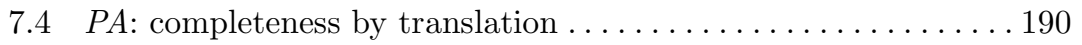

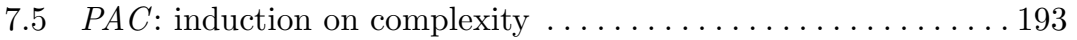

$7.6 \quad A M$ : translating action models . . . . . . . . . . . . . . . . . . 198

$7.7 \quad A M C$ : generalising the proof for $P A C \ldots \ldots \ldots \ldots \ldots \ldots \ldots \ldots$

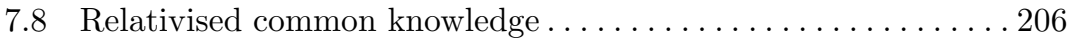

7.8.1 Language, semantics and completeness ........... 206

7.8 .2 Adding public announcements . . . . . . . . . . . 210

7.9 Notes . . . . . . . . . . . . . . . . . . . . . . . . . . . . . 213

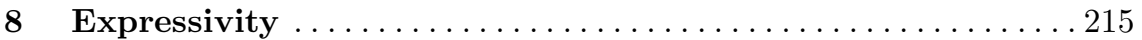

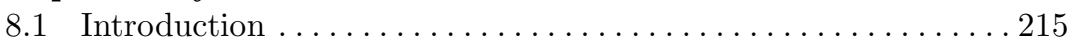

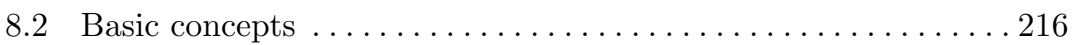

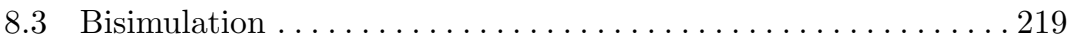

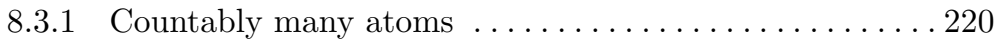

8.3 .2 Hedgehogs . . . . . . . . . . . . . . . . . . . . . . . . 221

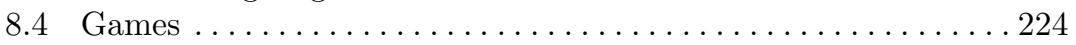

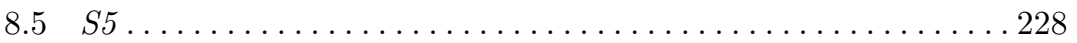

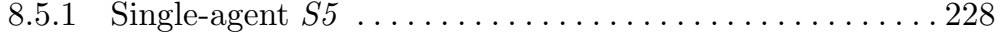

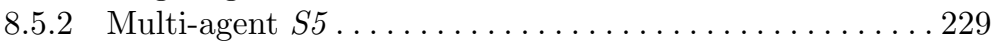

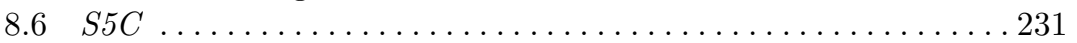

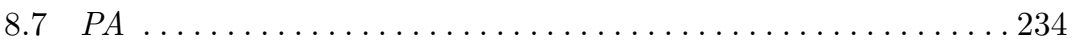

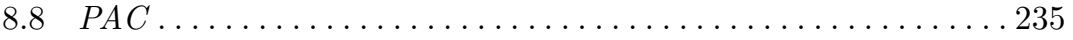

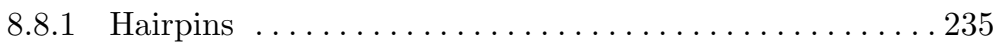

8.9 Non-deterministic choice $\ldots \ldots \ldots \ldots \ldots \ldots \ldots \ldots \ldots \ldots \ldots \ldots . \ldots \ldots 240$

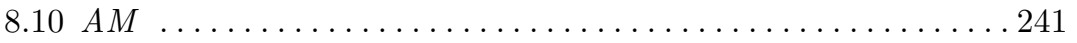

8.11 Relativised common knowledge . . . . . . . . . . . . . . 241

8.12 Notes . . . . . . . . . . . . . . . . . . . . . 246

Selected answers to exercises $\ldots \ldots \ldots \ldots \ldots \ldots \ldots \ldots \ldots \ldots \ldots \ldots$

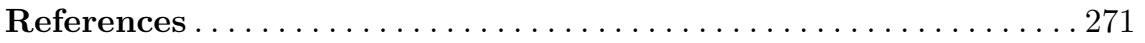

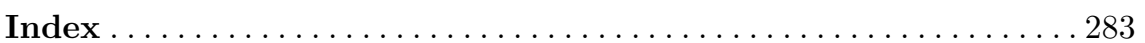





\section{Preface}

This is both a textbook and a monograph on dynamic epistemic logic. Dynamic epistemic logic is the logic of knowledge and change. The book consists of chapters

1. Introduction

2. Epistemic logic

3. Belief revision

4. Public announcements

5. Epistemic actions

6. Action models

7. Completeness

8. Expressivity

A common pattern in individual chapters is to introduce a logic by sections on structures, syntax, semantics, axiomatisation, applications, and notes. The structures are the same for almost all the logics discussed, namely multi-agent Kripke models. So the reader will not see these being reintroduced all the time. For most of the logics we present Hilbert-style axiomatisations. The somewhat substantial technical material involved in the completeness proofs for such axiomatisations has been addressed in a separate chapter, 'Completeness'. Examples for all concepts and logics introduced are found in running text and also as separate sections with applications, often analysing well-known logical puzzles and games in detail. The 'notes' sections give an overview of the historical record for the logic. That information is therefore omitted from other sections. Apart from examples, the running text also contains exercises. Selected answers to exercises from all chapters are found together at the back of the book.

A sweeping outline of the chapterwise content of this book is the following. Chapter 1, 'Introduction', explains why this book is about logic, about knowledge, and about change of knowledge; it also contains an overview of related topics that are considered out of focus and therefore not further mentioned in detail, such as temporal epistemic logic. Chapter 2, 'Epistemic logic', is 
an overview of and introduction into multi-agent epistemic logic - the logic of knowledge -including modal operators for groups, such as general and common knowledge. This may serve as a general introduction to those unfamiliar with the area, but with sufficient general knowledge of logic. Chapter 3, 'Belief revision', is a fairly detailed presentation on how to model change in a logical setting, both within and without the epistemic logical framework. This relates our modal approach to the area in artificial intelligence that is also named 'belief revision'. Unlike other chapters, it does not mainly model knowledge but also pays detailed attention to belief. Chapter 4, 'Public announcements', is a comprehensive introduction into the logic of knowledge with dynamic operators for truthful public announcements. Many interesting applications are presented in this chapter. Chapter 5, 'Epistemic actions', introduces a generalisation of public announcement logic to more complex epistemic actions; a different perspective on modelling epistemic actions is independently presented in Chapter 6, 'Action models'. 'Completeness' gives details on the completeness proof for the logics introduced in the chapters 2, 4, and 6. Chapter 8, 'Expressivity', discusses various results on the expressive power of the logics presented. As is to be expected - but with some surprises - the expressive power increases with the complexity of the logical language and corresponding semantics.

There are various ways in which a semester course can be based upon the book. All chapters are self-contained, so that one or more can be skipped if necessary. The core chapters are 2, 4, and 5. Another core path consists of Chapters 2, 4, and 6, in which case one should skip Section 6.8 that compares the approach of Chapter 5 with that of Chapter 6. Advanced classes, where familiarity with epistemic logic is assumed, will prefer to skip Chapter 2. A course focusing on technical logical aspects may consist of all the Chapters $2,4,5,6,7$, and 8 , whereas a course focusing on systems modelling will typically skip the Chapters 7 and 8 . Chapter 1 may be helpful for motivation to any audience. Chapter 3 is indispensable to an audience with an artificial intelligence or philosophical background.

The companion web-site to the book http://www.csc.liv.ac.uk/ $\operatorname{del}$ contains slide presentations, more answers to exercises, an overview of errata, sample exams, updated bibliographies, and other matters of educational or academic interest.

\section{Acknowledgements}

The plans for this book started with mutually encouraging contacts between Wiebe van der Hoek and Floor Oosting. We thank Floor Oosting for her encouragement throughout the project. Johan van Benthem has always been in the background, both as an advisor and continuously forwarding us potential users and lecturers. We owe him much. 
Input from many students of various graduate semester courses or summerschool courses have greatly helped. We thank the participants to ESSLLI Vienna, ESSLLI Edinburgh, the Logic and Automated Reasoning summerschool in Canberra, and the ILLC Master of Logic program. We are very grateful to many colleagues who provided us with input, in particular to those who read a pre-final version in detail before we handed it over to the publisher. We also thank the anonymous reviewer for the useful comments on our manuscript before it went to print. An incomplete list of people whom we owe thanks consists of, apart from those already mentioned: Thomas Ågotnes, Philippe Balbiani, Alexandru Baltag, Stefano Borgo, Elizabeth Coppock, Jan van Eijck, Jelle Gerbrandy, Paul Gochet, Andreas Herzig, Samson de Jager, Larry Moss, Eric Pacuit, Floris Roelofsen, Ji Ruan, Thomas Schneider, David Steiner, Peter Timmerman, Yde Venema, Rineke Verbrugge, and Mike Wooldridge.

Hans van Ditmarsch acknowledges support from the Netherlands Organisation for Scientific Research enabling a visit to the Netherlands in 2004, and support from the Science Division of the University of Otago freeing him for research time to complete this publication.

Dunedin, Liverpool, Groningen, October 2006
Hans van Ditmarsch Wiebe van der Hoek Barteld Kooi 